\title{
A historicidade da pesquisa em política educacional: o caso do Brasil
}

\author{
The historicity of education policy research: the case of Brazil
}

\section{Nora Krawczyk ${ }^{1}$}

\section{Resumo:}

O artigo apresenta uma discussão sobre as trajetórias históricas de constituição e tematização do campo de pesquisa em políticas educacionais no Brasil. O trabalho parte do reconhecimento que a consolidação da pesquisa em educação no Brasil iniciou-se nos anos de 1940 e logo na sequência as temáticas concernentes ao campo das políticas educacionais passaram a compor os objetos de investigação. Demonstrando os caminhos teóricos da constituição do campo, o texto indica, ao final, um conjunto de desafios para a pesquisa em políticas educacionais, destacadamente o necessário aprofundamento do debate teórico e histórico, a desnaturalização das categorias de análise e a articulação entre as diferentes áreas e abordagens teórico-metodológicas.

Palavras-chave: Políticas educacionais; pesquisa; campo de investigação.

\begin{abstract}
:
The article presents a discussion about the historical trajectories of constitution of educational policies research field in Brazil. The work considers that the consolidation of the research in education in Brazil was initiated in the years of 1940 and soon the thematic concerns to the field of the educational policies had started to compose research objects. Demonstrating the theoretical ways of the constitution of the field, the text indicates, at the end, a set of challenges for the research in educational policies, specially the necessary deepening of the theoretical and historical debate, the denaturalization of the analysis categories and the articulation between the different areas and methodological and theoretical approaches.
\end{abstract}

Keywords: Education policies; research; research field. 


\section{O Caráter Político}

Podemos dizer que a pesquisa em educação começou a consolidar-se no Brasil como um campo de estudo a partir na década de 40, século XX, aproximadamente, com a criação do Instituto Nacional de Estudos e Pesquisas Educacionais - INEP - e suas regionais em diferentes lugares do País "(...) a construção do pensamento educacional brasileiro, mediante pesquisa sistemática, encontrou espaço específico de produção, formação e estimulo" (GATTI, 2001, p.65).

Já nessa época, adquiriu um caráter político, sociológico e histórico. A preocupação passou do indivíduo, por meio do estudo psicopedagógico da aprendizagem, para a preocupação em compreender a relação entre educação e sociedade, com a intencionalidade de discernir qual é a função da educação nas relações sociais no País (GATTI, 2007). O clima político da época era extremadamente fértil para incentivar esse tipo de preocupação. O crescimento da industrialização, a partir da década de 1930, produziu um aumento importante das pressões sociais pela educação pública e, principalmente, pela formação dos trabalhadores. Nessa época, foi criado o Ministério de Educação e Saúde, como uma expressão de que a educação pública começava a ser reconhecida como uma questão nacional, ainda que isso não tenha significado, necessariamente, a responsabilização do Estado nacional pelo provimento de ensino público.

Na sequência, tivemos uma série de fatos históricos no Brasil que demonstravam a arena de conflitos que se tornou a educação pública no âmbito nacional. Entre eles, o Manifesto dos Pioneiros da Educação Nova, que apontava a necessidade de constituição de um sistema educacional, a Constituição de 1934, que colocava a importância de definir diretrizes nacionais para educação, o longo processo de tensões de mais de uma década para a promulgação da primeira Lei de Diretrizes e Bases, o desenvolvimento do sistema de educação profissional, mas com transferência desse encargo para o setor privado, etc.

Mas o aceleramento do desenvolvimento da pesquisa em educação - e especificamente em política educacional -, na segunda metade do século XX, deve-se, também e, principalmente, à implantação de um vasto conjunto de programas de pós-graduação no País, no final da década de 1960, pelo qual se transferiu para as universidades o espaço de produção científica e de formação de quadros e criou-se o Sistema Nacional de Pós-Graduação.

\section{Escolarização da Produção Científica}

A institucionalização da pesquisa, conjuntamente com a institucionalização da pós-graduação em educação, diferentemente de outros países, trouxe como consequência uma forte associação entre atividades de formação e de produção de conhecimento; e, principalmente, a burocratização do trabalho científico, o que se reflete no que poderíamos denominar de escolarização da produção científica. Por isso, é comum encontrar produções acadêmicas associadas a diplomas, determinada por uma organização e um formato que expresse os requisitos institucionais e os tempos preestabelecidos. Ao mesmo tempo, a concentração da pesquisa na pós-graduação tem produzido uma "dupla rede" no ensino superior: na graduação, na docência; na pós-graduação, na pesquisa; fragmentando e hierarquizando as atividades acadêmicas (CURY, 2004).

A criação das universidades brasileiras com a formatação que conhecemos hoje, com forte investimento na pós-graduação e na pesquisa, está vinculada ao projeto de modernização conservadora do capitalismo, implementado pela ditadura militar que governou o País entre os anos de 1964 e 1985. A formação de recursos humanos de alto nível articulada às necessidades do mercado e, por tanto, do setor produtivo, era vista como necessária para o desenvolvimento, considerando-a essencial para o sucesso do projeto modernizador em curso (AZEVEDO, 2004). 


\section{Contrapondo-se à ideia de Capital Humano}

Durante a década de 1960, a pesquisa em educação apresentou forte influência da área da economia, ganhando destaque nos estudos sob a perspectiva da Teoria do Capital Humano, posição coerente com a política do País, que passou a privilegiar o planejamento de custos, a eficiência e as tecnologias no ensino profissionalizante (GATTI, 2001).

$\mathrm{Na}$ década de 1970, as áreas de concentração predominantes nos 17 cursos de mestrado em educação em funcionamento eram: administração de sistemas educacionais, ensino, aconselhamento psicopedagógico, filosofia da educação e planejamento educacional. Desse total, 10 cursos tinham como área de concentração a administração de sistemas educacionais. Tal como afirmam Santos e Azevedo, isso pode ser tomado como reflexo da concepção tecnicista, então predominante, na qual uma das principais causas dos problemas da educação era identificada na má administração dos sistemas e das escolas (SANTOS \& AZEVEDO, 2009).

Entretanto, a pesquisa não se restringiu a responder às demandas estatais. Ainda que sob um processo ditatorial e apesar de sua orientação repressora e conservadora na produção e na divulgação científica, iria desenvolver-se uma estrutura universitária que, junto com diversos movimentos sociais, produziu consequências políticas e culturais, em boa parte, contrárias aos interesses da ditadura. Assim, as universidades foram criando uma produção crítica ao sistema e, junto com o descrédito de soluções técnicas, o perfil da pesquisa enriqueceuse com novas perspectivas teóricas e metodológicas.

Nesse contexto, a área de estudo das políticas educacionais, que estava focada, principalmente, nos estudos de administração escolar, começou a estabelecer diálogo com outras perspectivas teóricas, sobretudo, marxistas, que levaram à construção de uma perspectiva crítica da administração escolar. Esse diálogo fortaleceu-se durante o processo de transição democrático na década de 1980, época de consolidação e expansão da pós-graduação.

As perspectivas críticas da administração escolar influenciaram e continuam influenciando bastante o debate e a produção acadêmica em torno da democratização da gestão do sistema educacional e da escola. Nos últimos anos, tem sido também um contraponto às teorias da administração empresarial e ao discurso da eficácia institucional.

O retorno à democracia política trouxe uma intensa mobilização social pela educação e o entusiasmo pelo estudo da educação no marco das relações sociais capitalistas, com base em autores estrangeiros e brasileiros de inspiração marxista, especialmente nas áreas de história, filosofia, administração e politica educacional. Conjuntamente à participação social, a educação passou a ser vista como possibilidade de democratização e de reversão da lógica centralizadora e autoritária da ditadura.

Esse clima sociopolítico influenciou bastante a escolha dos temas de pesquisas em política educacional da época, que continua ocupando um espaço importante, ainda hoje: os estudos de educação de adultos e uma crítica radical à escola, questionando a ideia de que a democratização do acesso à escola resolveria o problema da educação das classes trabalhadoras. Um foco importante dos debates nos fóruns de Educação na década de 1980, e que influenciaram os interesses de pesquisa na área, foi a repercussão na sociedade brasileira do processo politico autoritário e no âmbito politico educacional, especialmente na legislação, na distribuição de recursos e na gestão da educação, levando a priorizar temas como: a relação entre educação e sociedade; a participação; a autonomia escolar; o financiamento, entre outros.

\section{Relações entre educação e trabalho}

Neste contexto, um tema igualmente importante que ampliou o impacto e a hegemonização da matriz marxista no campo da educação foi o das relações entre educação e trabalho, no bojo dos debates sobre a 
profissionalização do ensino médio e da reforma universitária propostas pelo regime autoritário².

O desenvolvimento desse pensamento crítico em educação trouxe intensa influência de autores como Marx, Gramsci, Foucault, Althússer, Bourdieu, Adorno, Florestan Fernandes, Paulo Freire, Dermeval Saviani, Luis Antonio Cunha e outros.

Segundo Brandão (2005, p. 6)

a ampliação dos programas de pós-graduação naquele panorama temático e teórico, fomentou os debates sobre as relações entre educação (escolar) e a construção de uma sociedade democrática, que desde as primeiras décadas do século XX, com os Pioneiros da Escola Nova³ , não havia sido retomado com tanta força, entre nós.A pesquisa de Luiz Antônio Cunha (1975) publicada sobre 0 título de Educação e Desenvolvimento Social no Brasil tornou-se uma referência obrigatória porque desmistifica, com dados empíricos, o binômio desenvolvimento e educação, que legitimou a politica educacional desenvolvida no período militar brasileira pós 1964, enfatizando o efeito ideológico de atribuir à educação as mudanças sociais. E, significou, segundo Brandão (2005, p. 6), “... um avanço importante na direção de uma maior atenção para a leitura dos fenômenos empíricos, em uma época em que os discursos teóricos sobrepunham-se aos fenômenos concretos da sociedade e da educação".

\section{A escola como espaço de luta hegemônica}

Entre as influencias mais marcantes dessa época, na pesquisa educacional (história, filosofia e política educacional) vale citar também a polêmica desencadeada por Dermeval Saviani no livro Escola e Democracia, editado por primeira vez em 1983, no qual argumenta sobre a necessidade de uma nova teoria e uma visão alternativa superadora às visões, que segundo o autor, se acreditavam progressistas, consubstanciadas na Teoria Pedagógica Histórico-Crítica.

Saviani vai contrapor ao princípio da reprodução, a afirmação da escola como espaço de luta hegemônica entre as classes fundamentais da sociedade capitalista é, portanto, um espaço cheio de contradições. Esta polêmica deu novo fôlego ao debate e pesquisa em política educacional no Brasil e em outros países latino-americanos, introduzindo a análise não somente no caráter reprodutor da escola como também dos espaços de contradição discussão e de luta hegemônica nos diferentes níveis de elaboração e de implementação de políticas.

Os anos 1980 foram fecundos para o debate teórico-metodológico entre pesquisadores em educação, em muitos casos rebatendo o enfoque quantitativo e qualitativo de pesquisa. Foi um momento de um forte incremento de pesquisas qualitativas na área da educação, como consequência da intensa crítica às estratégias de medição e quantificação da realidade. As críticas concentraram-se, principalmente, na incapacidade do enfoque quantitativo para compreender e explicar as motivações e os comportamentos dos indivíduos e dos grupos sociais, os processos sociais e educacionais e sua relação com a estrutura social, as dinâmicas institucionais, entre outros.

Esse embate teórico-metodológico apresentou certa particularidade na área de pesquisa em política educacional, no qual estavam presentes ambos os enfoques, cada um deles privilegiando temáticas distintas. A mobilização social, por aumento do orçamento para educação e das mudanças ocorridas no âmbito da gestão do financiamento público para a área e nas responsabilidades e nas atribuições dos diferentes entes federados com educação, principalmente a partir de finais da década de 1980, promoveram o fortalecimento de linhas de pesquisa sobre financiamento da educação; e, ao mesmo tempo, a pesquisa qualitativa passou a focar seus

2 A reforma Universitária realizada em 1968, imposta pela ditadura militar, foi parte da intervenção americana, por meio de diferentes acordos, no ensino superior brasileiro. A Reforma foi concebida como uma estratégia militar de afrontamento ao movimento estudantil que reclamava pela democratização do ensino, incorporando alguns aspectos modernizantes, tais como: a introdução da organização departamental; a unificação do vestibular passando a ser classificatório; 0 aglutinamento das faculdades em universidades, visando a uma maior produtividade com a concentração de recursos; a divisão do currículo em dois ciclos: um básico e outro profissionalizante; a integração de ensino e pesquisa e a ênfase na pós-graduaçã̃o, entre outros.

30 Manifesto dos Pioneiros da Escola Nova de 1932 consolidava a visão de um segmento da elite intelectual que vislumbrava a possibilidade de interferir na organização da sociedade brasileira do ponto de vista da educação. 0 documento se tornou o marco inaugural do projeto de renovação educacional do país, que além de constatar a desorganização do aparelho escolar, propunha que o Estado organizasse um plano geral de educação e defendia a bandeira de uma escola única, pública, laica, obrigatória e gratuita. 
estudos nas gestões governamentais e institucionais.

É interessante destacar que ambos os enfoques metodológicos possuem muito poucos canais de comunicação e produção conjunta na área de política educacional, o que talvez seja motivado pela pouca experiência em pesquisas com enfoques quantitativos e qualitativos e por uma tendência mais geral de colocálos como procedimentos metodológicos antagônicos, o que cria uma mútua desvalorização.

\section{O caráter científico em questão}

As maiores dificuldades encontradas nas pesquisas qualitativas produzidas nas últimas décadas consistem em identificar e construir analiticamente os processos sociais e educacionais, por meio do diálogo com perspectivas teóricas e com a produção científica coletiva nacional e internacional, possibilitando ao pesquisador sair do contexto particular do estudo em questão e da mera descrição da realidade tal qual como se manifesta, para alcançar a compreensão do fenômeno como processo social (ANDRÉ, 2001; GATTI, 2001).

A literatura sobre o tema mostra-nos também a necessidade de uma formação sólida e domínio das técnicas, para a apropriação da realidade e para sua reconstrução e revela que a riqueza da pesquisa qualitativa não está na possibilidade de aplicar seus resultados a locais e sujeitos semelhantes (sentido convencional de generalização), mas em sua propriedade de criar conhecimentos (afirmações) universais sobre os processos sociais gerais (BOGDAN; BIKLEN, 1994; CHIZZOTTI, 1991; MARRADI et al., 2007).

A história recente - nacional, regional e internacional - tem produzido certo descrédito na política e no sentido do público e, ao mesmo tempo, tem sido bastante fértil para a pesquisa em política educacional. As intensas transformações sociais, políticas e econômicas provocam novos problemas de pesquisa, categorias de análise e diálogos com outras áreas científicas.

As pesquisas que estudam a relação entre educação e sociedade passaram a ser bastante criticadas no discurso hegemônico internacional e nacional, sob o argumento de serem "muito ideológicas"; e, ao mesmo tempo, os estudos de política educacional incrementam-se. De um lado, outras linhas de pesquisa incorporam uma mirada político-educacional, numa perspectiva pós-estruturalista, focando seus estudos sob a ótica da preocupação pela diversidade de formas culturais e identidade, privilegiando temas como formação de professores, livro didático, currículo e multiculturalismo, práticas escolares, gênero, infância, dentre outros. De outro lado, a reforma educacional implantada nos diferentes países da América Latina no limiar do século XXI, consoante às mudanças sociais, políticas e econômicas da época, trouxe transformações sistemáticas bastante significativas na educação pública que, ao mesmo tempo, produziram importantes impactos nas relações entre Estado, educação e sociedade.

\section{Os dois eixos da reforma}

De maneira muito sintética, podemos dizer que essa reforma educacional apresentou dois eixos principais que se manifestaram também nas políticas educacionais brasileiras: a reorganização e a gestão do sistema educacional e da unidade escolar. A primeira foi impulsionada, dominantemente, pela municipalização do ensino fundamental, pela criação das diretrizes curriculares nacionais, pela separação do ensino médio regular e profissional e pela criação do Fundef ${ }^{4}$. As mudanças na gestão escolar foram promovidas pelo aumento de responsabilidades da equipe da escola e da comunidade, pela liberalização de certas atribuições para a unidade escolar e para os pais e pelo novo perfil desejado para a direção escolar.

Tais políticas induziram os pesquisadores a aprofundar, sobretudo, os estudos sobre gestão, participação, dinâmicas federativas e financiamento da educação.

Neste marco, encontramos frequentemente na pesquisa acadêmica -especialmente no âmbito do mestrado e

4 Fundo de Manutenção e Desenvolvimento do Ensino Fundamental e Valorização do Magistério 
doutorado - uma abordagem descritiva que resgata experiências alternativas e contestatórias à reforma educacional. São, principalmente, experiências municipais de gestão democrática da educação - na maioria implementadas pelo Partido dos Trabalhadores (PT). São estudos que focalizam aspectos específicos da gestão da educação e/ou da escola, segundo as orientações teóricas, utilizando dados empíricos de pequena escala e uma análise de cunho qualitativo. Ainda que muitos desses estudos pretendesse realizar uma reflexão sobre as experiências registradas, geralmente o envolvimento pessoal dos pesquisadores nesses projetos político-educacionais comprometeu o distanciamento entre o campo acadêmico e o campo de atuação política, dificultando a realização de uma análise da situação, conceptualização e produção de novo conhecimento (KRAWCZYK \& VIERA, 2008; CAMPOS, 2009).

No entanto, além da especificidade da política nacional e local, a pesquisa sofreu também influência das tendências regional e internacional. Por exemplo, os organismos internacionais foram importantes indutores não somente das reformas educacionais implementadas em diferentes países como também de enfoques na produção de conhecimento na área da educação. Nesse sentido, dois outros tipos de abordagens têm uma presença significativa nos últimos 20 anos no estudo das políticas educacionais: os registros de experiências e as pesquisas comparadas.

Conjuntamente, é possível observar, a importância crescente de outros espaços de produção de pesquisa sobre educação que não os acadêmicos (instituições independentes de pesquisa, organizações não governamentais e institutos empresariais), sob a justificativa de falta de objetividade na pesquisa acadêmica, distanciada dos problemas educacionais considerados mais urgentes e, portanto, pouco proveitosa para aqueles que precisam tomar decisões sobre política educacional. Financiamentos substantivos, governamentais e internacionais, foram assim dirigidos às instituições com perfis mais pragmáticos, que se dispusesse a oferecer resultados em curto prazo, na maior parte das vezes de acordo com encomendas definidas externamente às equipes de pesquisa5. (CAMPOS, 2009).

Tal como afirma Campos, mais do que perguntar para que serve a pesquisa, deveríamos "indagar à academia sobre as influencias que sofre a partir da dinâmica social”. (CAMPOS, 2009. p. 274)

Os registros de experiências são estudos descritivos para divulgar práticas governamentais e/ou institucionais inovadoras e exitosas, segundo os pressupostos da Reforma Educacional, que surgiram na década de $1990 \mathrm{em}$ diferentes países latino-americanos, com o propósito de que possam tornar-se referências para serem adotadas por governos e instituições dos demais países da região.

Num momento em que muitos se perguntam qual é o melhor caminho a seguir para melhorar a eficácia das políticas e a qualidade da escola, as respostas rápidas de "como fazer", os "modelos" ou "receitas" tornam-se bastante atraentes.

Encontramos com frequência o registro de experiência, principalmente, na produção do limiar do século XXI. Tal registro resultou do propósito de incentivar políticas educacionais através de referências a situações nacionais, regionais ou internacionais, por um mecanismo de "contaminação”6 de políticas postas em prática em outros locais.

\section{A pesquisa comparada}

Outra abordagem metodológica que nos últimos dez anos vem progressivamente tomando cada vez maior fôlego na pesquisa em política educacional é a pesquisa comparada.

Com um extraordinário desenvolvimento na segunda metade do século $X X$, no bojo do processo de reconstrução internacional do capitalismo democrático concebido no marco da teoria desenvolvimentista, a pesquisa comparada teve como alvo estabelecer comparação entre as características e o desenvolvimento dos sistemas educacionais de diferentes países, com o objetivo de fornecer subsídios para a formulação e a implementação de políticas de desenvolvimento educacional nos países periféricos.

5 Essa tendência na pesquisa educacional no Brasil faz parte de um movimento internacional que defende a importância dos resultados de pesquisas experimentais para a tomada de decisões políticos educacionais e nas práticas pedagógicas nas escolas, porque estariam oferecendo respostas objetivas às decisões e práticas no campo da educação. Essa tendência que vêm ganhando força, principalmente, nos EE.UU (principalmente no governo Bush) e no Reino Unido.

6 Conceito utilizado por Barroso, 2006. 
Na América Latina, a pesquisa educacional crítica foi se afastando cada vez mais do enfoque comparativo, em decorrência da forte associação com o paradigma positivista e com a política imperialista de desenvolvimento. De tal modo que, ocorreu esse distanciamento, tornando-se, praticamente, inexistentes, do ponto de vista crítico, as produções acadêmicas que contemplassem análises comparativas.

Na década de 1990, retomaram-se os estudos comparados, principalmente nas áreas de política educacional e gestão escolar.

Os estudos surgiram, num primeiro momento, encomendados e divulgados pelos organismos internacionais que, ancorados no enfoque teórico-metodológico funcionalista, possibilitaram o reforço do caráter homogeneizador, tanto na leitura das realidades nacionais quanto nas propostas para impor uma padronização de política educacional na região.

Entretanto, aos poucos os estudos comparados também vêm sendo utilizados para a compreensão de processos educacionais que ultrapassam as fronteiras do Brasil. Tais estudos têm se mostrado interessantes para distinguir as tendências regionais das especificidades nacionais e/ou locais. Mas, em algumas ocasiões, pela ausência de uma pergunta de pesquisa que justifique a necessidade da comparação e/ou pelo pouco conhecimento dos países analisados, a pesquisa acabou reduzindo-se à constatação de convergências entre as situações nacionais, sendo pouco explorado o enfoque comparativo como recurso analítico e interpretativo.

No estágio de globalização do capitalismo atual, no qual estamos vivendo o intento sistemático de tornar uniformes as políticas nacionais através, entre outros, de condicionantes supranacionais, a pesquisa comparada tem um potencial muito rico de interpretação, se levar em conta as historicidades nacionais para a análise das convergências e as especificidades na concretização de políticas globais. Mas, este enfoque, ainda, deve ser mais explorado. É o desafio da passagem da análise dos fatos para a análise do "sentido histórico dos fatos" (NÓVOA, 1995).

Com foi possível observar nesta rápida síntese sobre o desenvolvimento da pesquisa em educação no Brasil, para compreender o teor da pesquisa em política educacional é necessário levar em conta um conjunto de fatores que afetam o desenvolvimento da produção científica em cada país. Os espaços institucionais onde se realizam as pesquisas, as especificidades nacionais e historicidade, o clima político e o contexto histórico e as influências do debate internacional alimentam os olhares dos pesquisadores e revelam-se na escolha dos temas, das categorias, isto é, revelam-se no caráter do conhecimento produzido?.

A educação remete-nos a um conjunto de situações, de práticas, de políticas resultantes de uma prática social e, portanto, está intimamente ligada às relações sociais historicamente determinadas, que precisam de diferentes abordagens disciplinares para sua compreensão e análise. Contudo, o diálogo da educação com as diferentes áreas disciplinares não se dá de forma simultânea, pois a preocupação destas com a educação - e vice-versa - está relacionada aos problemas e aos desafios que a realidade nos apresenta.

\section{Um diálogo transdisciplinar}

Sinteticamente, vimos o contexto no qual acontece a influência da economia e da administração escolar, principalmente na perspectiva critica, nos estudos sobre política educacional no Brasil. No entanto, ainda existe pouco diálogo com outras abordagens disciplinares, tais como a sociologia da educação, que nas últimas décadas tem incorporado à análise do Estado e suas contradições; da relação entre o Estado e a sociedade; e das relações sociais (relações de poder, grupos de interesses, correlação de forças, etc.) na compreensão dos processos de definição e implementação de política educacional e das práticas educativas. Esta abordagem vem instaurando um novo campo de estudo da sociologia: o estudo sociológico das políticas educacionais (BONAL, 1998; TORRES, 2000).

Essa abertura da sociologia ao estudo das políticas educacionais está, claramente, vinculada ao caráter das

7 A pesquisa sobre a Reforma Educacional na década de 1990 em vários países latino-americanos que realizei conjuntamente à profa. Dra Vera Lucia Vieira evidencia de forma bastante clara a importância da historicidade dos países para compreender a produção científica. Ver: Krawczyk, N. e Vieira, V. L., 2008. 
reformas que aconteceram nas últimas décadas nas diferentes regiões, que resultaram da crise do Estado de bem estar e suas repercussões sobre as contradições que enfrenta o Estado capitalista.

Por exemplo, a literatura inglesa, principalmente, e parte da literatura americana realizaram, nas últimas décadas, aportes importantes para a compreensão do processo de mercantilização da educação, suas consequências na prática educativa e o impacto sobre a desigualdade educacional e social.

Nos últimos anos, embora ainda incipiente, vem crescendo a preocupação na incorporação da dimensão histórica na pesquisa em educação. Ainda pouco se levava em conta a historicidade dos processos educacionais, naturalizando as categorias de análise ao não compreender e/ou não explicitar a historicidade que carregam.

\section{Desafios atuais para a pesquisa em política educacional}

Muitos são os desafios que acompanharão a pesquisa em política educacional nos próximos anos, mas gostaria, para terminar, destacar alguns: revigorar o debate teórico e histórico. A pesquisa empírica é fundamental para o conhecimento aprofundado da realidade, mas, para poder organizar e analisar os dados coletados é necessária uma direção que permita interpretar os aspectos singulares da realidade observada e integrar as pesquisas no todo maior de produção científica. A preocupação com as dimensões teórica e histórica possibilitará à pesquisa interpelar as políticas educacionais e a realidade educacional concretizada como processos que carregam historicidade. Dessa forma, é possível colaborar com a desnaturalização das categorias de análise, identificando os espaços de continuidade e ruptura e superando o limite da inevitabilidade, tão pernicioso para a produção científica. Articular as diferentes áreas e abordagens teórico-metodológicas de pesquisa em política educacional. O fortalecimento do debate entre os pesquisadores para discutir os resultados de suas pesquisas e um maior diálogo entre as produções com diferentes enfoques metodológicos ajudaram a criar um ambiente coletivo de produção científica e otimizar a área de política educacional. Aprofundar o diálogo com outras áreas de conhecimento do campo de estudo em educação e fora dele, em nível nacional e internacional.

Sendo a educação um campo de estudo interdisciplinar, é um desafio para nós que o integramos fortalecer esse campo de conhecimento através do diálogo entre as diferentes áreas, para ter uma compreensão cada vez mais cabal da situação da educação, resgatando a especificidade no âmbito das relações e das práticas sociais.

\section{Aprimorar as pesquisas e repensar a política de pós-graduação no país}

Segundo dados fornecidos pela CAPES, até maio de 2012, o Brasil, contava com 112 programas de pós-graduação em educação, sendo 51 cursos de mestrado, 60 cursos de mestrado e doutorado e 11 mestrados profissionalizantes.

A aceleração do desenvolvimento da área de pesquisa em educação articulado com a implementação da pós-graduação permite hoje afirmar que é no âmbito da pós-graduação que, efetivamente, a prática de pesquisa acontece (ANDRÉ, 2001).

O caráter interdisciplinar do campo de conhecimento em educação torna a formação do pesquisador, em qualquer uma das áreas, uma tarefa bastante complexa, já que não é possível pensar num conhecimento "unidirecional".

Além disso, a pesquisa na pós-graduação representa uma porcentagem bastante significativa da pesquisa no Brasil, é necessário discutir sobre as condições nas quais ela vem sendo produzida.

Não render-se às demandas imediatistas nem às ansiedades para encontrar respostas rápidas e "mágicas". Isto não quer dizer que não devamos levar em conta os problemas concretos que surgem no cotidiano da educação - é aí que os problemas ganham corpo -, mas a pesquisa não pode estar a serviço de solucionar pequenos impasses do cotidiano. O tempo de maturação do processo de construção de conhecimento (individual e coletivo) não é o mesmo que o das decisões políticas, o das necessidades dos professores e o dos gestores da educação. A profa. Gatti (2006, p.29) adverte que os espaços da academia e da gestão "possuem temporalidades diversas e suas interações são complexas, construídas no bojo das relações sociais concretas".

Assumir a tensão entre o campo acadêmico e o campo de atuação política, fronteira bastante sensível na área 
de política educacional. Produzir conhecimento novo e socialmente significativo, que incorpore uma reflexão, numa perspectiva de longo prazo e que não exclua alguns assuntos sob o argumento da inevitabilidade de algumas situações. Relegar algumas dessas questões é negar a sua problematização social (OSLAK; O'DONNELL, 1981).

A busca de uma pergunta adequada, da questão que não tem resposta evidente é que constitui o ponto de origem de uma pesquisa científica.

\section{Referências Bibliográficas}

ANDRÉ, M. Pesquisa em educação: buscando rigor e qualidade. Caderno de Pesquisa - FCC, São Paulo, n. 113, jul. 2001.

AZEVEDO, J. M. L. As humanidades no contexto da pós-graduação brasileira. In: DOURADO, L. F.; et al. (Org.). Avaliando as políticas e gestão da educação no Brasil. Brasília: INEP, 2004, v. 1, p. 35-56.

BOGDAN, R.; BIKLEN, S. Investigação qualitativa em educação. Uma introdução à teoria e aos métodos. Porto: Porto Editora, 1994.

BONAL, X. Sociologia de la Educación. Una aproximación crítica a las corrientes contemporâneas. Barcelona: Paidós, 1998.

BRANDÃO, Z. Pesquisa em educação. O olhar do nadador: do individual ao coletivo. Educação On-Line, Rio de Janeiro, v. 1, p. 1-15, 2005.

CAMPOS, M. M. Para que serve a pesquisa em educação?. Cadernos de Pesquisa, vol. 39 no. 136, São Paulo, jan./abr. 2009.

CHIZOTTI, A. Pesquisa em Ciências Humanas e Sociais. São Paulo: Cortez, 1991.

CUNHA, L.A. R. (1975) Educação e Desenvolvimento Social no Brasil. Rio de Janeiro: Francisco Alves.

CURY, C. R. J. Graduação/pós-graduação: a busca de uma relação virtuosa. Educação e Sociedade, Campinas, v. 25, n. 88, p. 777-793, out. 2004.

GATTI, B. Implicações e perspectivas da pesquisa educacional. Caderno de Pesquisa — FCC, São Paulo, n. 113, jul. 2001.

. A Pesquisa na pós-graduação e seus impactos na educação. Educação \& Linguagem, v.9, n.14, p.16-33, jul./dez. 2006

A construção da pesquisa em Educação no Brasil. Brasília: Liberlivro, 2007.

MARRADI, A.; ARCHENTI, N.; PIOVANI, J. Metodologia de las Ciencias Sociales. Buenos Aires: Emecé, 2007. NÓVOA, A. "Modelos de análise em educação comparada: o campo e a carta". Les Sciences de l'education pour l'ère nouvelle, n 2-3/1995.

OSZLAK, O.; O'DONNELL, G. Estado y políticas estatales en América Latina: hacia uma estratégia de investigación. Buenos Aires: Centro de Estudios de Estado y Sociedad (CEDES), 1981. (Documentos CLACSO, n. 4).

SANTOS, A. L. F.; AZEVEDO, J. M. L. A pós-graduação no Brasil, a pesquisa em educação e os estudos sobre a política educacional: os contornos da constituição de um campo acadêmico. Revista Brasileira de Educação. v. 14 n. 42 set./dez. 2009

TORRES, C. A. Educação, poder e biografia pessoal. Diálogo com educadores críticos. Porto Alegre: Artmed, 2000.

Recebido em agosto de 2012 Aprovado em Outubro de 2012 